\title{
Doppler Echocardiographic Evaluation of HIV-Positive Patients in Different Stages of the Disease
}

\author{
Guilherme Lobosco Werneck, Evandro Tinoco Mesquita, Luiz José Martins Romêo Fo, Mario Luiz Ribeiro \\ Rio de Janeiro, RJ - Brazil
}

\begin{abstract}
Objective - To evaluate by Doppler echocardiography (DE) early abnormalities of ventricular function in $H I V$-positive patients, as well as other cardiac abnormalities that can be detected by this method, with special emphasis on mitral valve flow.
\end{abstract}

Methods - $84 \mathrm{HIV}$ - positive patients, 59 with CD4 cell count $>500 / \mathrm{mm}^{3}$ (Group A) and 25 with CD4 cell count $<500 / \mathrm{mm}^{3}$ (Group B), were analyzed. CD4 cells were counted and matched with structural data and systolic and diastolic function of the left ventricle ( $L V)$, as analyzed by $D E$. The results were compared with those obtained in 47 healthy individuals (Group C).

Results - 8\% of patients in Group B had mild pericardial effusion; $31.5 \%$ showed decreased systolic function of the $L V$, and $12 \%$ had moderate mitral regurgitation. A wave velocity from the mitral inflow was different among the 3 groups, being higher in Group B, where the deceleration time of the $E$ wave of the mitral inflow and the $E / A$ ratio were significantly lower with a normal value of the isovolumic relaxation time (IVRT).

Conclusion - HIV-positive patients with a CD4 cell count $>500 / \mathrm{mm}^{3}$ had no abnormalities by DE. Patients with a more advanced infection (those with a CD4 cell count $\left.<500 / \mathrm{mm}^{3}\right)$, had a significantly abnormal LV systolic function and a higher incidence of pericardial effusion and mitral regurgitation. Mitral valve inflow by Doppler did not indicate diastolic dysfunction.

Key words: Doppler echocardiogram, AIDS, mitral flow

Universidade Federal Fluminense - Rio de Janeiro

Mailing address: Guilherme Lobosco Werneck - Rua Barão de Mesquita 600/803

- Rio de Janeiro, RJ Brazil

Received on 6/9/98

Accepted on $3 / 24 / 99$
Human acquired immunodeficiency syndrome (AIDS) was initially recognized in the United States in $1981^{1,2}$. Later, in 1984, the human immunodeficiency virus (HIV 1) was recognized as the causal agent ${ }^{3}$. According to the World Health Organization, about 18 million people are infected by HIV 1 and 4.5 million have AIDS ${ }^{4}$. In the next century, it is estimated that approximately 30 million are going to be infected. In Brazil, data from the last epidemiological bulletin, published in August 1997, show that 116,389 persons have AIDS, a ratio of $83.4 / 100,000$ inhabitants.

AIDS is a viral disease that characteristically causes a chronic, insidious infection, with a long latent period, which is characterized by a profound state of immunosuppression, especially of cell immunity, with functional abnormalities in B lymphocytes, with polyclonal activation but without adequate antigen specific response.

Human T lymphocytes, which express the CD4 antigen on their surfaces, are the major targets of HIV 1.CD4 antigen works as a high-affinity receptor for a glycoprotein of the viral envelope (gp 120). After the virus enters the cell, there is transcription of the viral RNA into double-stranded DNA, which is then incorporated into the cellular nucleus, originating proviral DNA. Expression of the HIV gene is stimulated by several factors, leading to the production of the HIV virion that causes cell death and restarts the cycle, infecting other target cells. Depletion of CD4 positive T lymphocytes leads to the immunodeficiency observed in the disease ${ }^{5}$.

It has not yet been completely clarified how HIV 1 causes the cytopathic effects upon T lymphocytes. One hypothesis is fusion of infected cells and formation of syncytia, mediated by the viral envelope glycoprotein gp 41 following the interaction of the CD4 receptors with the glycoprotein gp 120. Other hypotheses are the following: apoptosis or cell death programmed by activation of endonucleases; a high level of viral replication resulting in damage to the cell membrane; production of tumor necrosis factor - alpha (TNF-alpha); and autoimmune destruction of T lymphocytes through antibody-dependent mechanisms ${ }^{6,7}$.

Glycoprotein gp 120 also binds to the surface of monocytes, macrophages and dendritic cells. After the 
primary infection, there is a long period of clinical latency. Antibodies anti-HIV-1 may be detected in the serum, but the disease is clinically asymptomatic or minimally symptomatic. This latent period usually lasts 10 years, in which there is evidence of continuous viral replication in the lymph nodes; however, serum levels of HIV are low and a small proportion of CD4 positive lymphocytes are infected. Development of AIDS is preceded by an increase in the depletion of these lymphocytes ${ }^{8-10}$.

Although cardiac involvement in HIV- infected patients has been recognized on autopsy ${ }^{11}$ since the beginning of the epidemy, cardiovascular disease specifically related to the syndrome has a low prevalence. Clinical manifestation of cardiac disease was only just reported in $1986^{12}$, and the first prospective study to evaluate cardiac function was conducted in $1988^{13}$. Clinical manifestations are LV dysfunction and congestive heart failure (CHF), pericardial effusion sometimes causing cardiac tamponade and ventricular tachycardia ${ }^{12-16}$.

Some authors have said that, although clinical cardiac involvement has a low incidence in AIDS patients, autopsy studies show a significantly higher cardiac involvement ${ }^{17,18}$.

Other studies have shown a more significant cardiac involvement, such as myocarditis, ventricular dilation, neoplastic infiltration ${ }^{19}$, pericarditis, pericardial effusion and thrombotic (nonbacterial) endocarditis ${ }^{20-25}$.

The most frequently reported clinical problem in cardiac involvement in HIV-infected patients is pericarditis, with or without pericardial effusion, which is related to several etiologies ${ }^{26-33}$; prevalence as determined by DE is about $38 \%{ }^{5}$.

Primary pulmonary hypertension $(\mathrm{PH})$ has also been described in AIDS patients ${ }^{34}$.

Cardiomyopathy is rare in patients with HIV infection and is more commonly identified by anatomo-pathology studies ${ }^{35}$. When the diagnosis of myocardial involvement is based on $\mathrm{LV}$ function or dilation by $\mathrm{DE}$, the prevalence is high $^{36-38}$. Corallo et al ${ }^{39}$, using DE, reported a $41 \%$ incidence of LV hypokinesis in $102 \mathrm{HIV}$ - infected patients. Two prospective studies ${ }^{35,40}$ show that patients developed LV dysfunction sometime during the evolution of the disease. Cardiovascular involvement by some opportunistic agents and by neoplasias has also been described ${ }^{41}$.

In Brazil, HIV infection is an emerging public health problem. The heterogeneity of the viral aggression is well known in different populations, but there is not a Brazilian study of the morpho-functional analysis that correlates abnormalities revealed by DE in different stages of the disease. This is the objective of this study.

\section{Methods}

Patients infected by the human immunodeficiency virus Type I (HIV 1) were evaluated in the Nucleo of AIDS and Sexually Transmitted Diseases of the Secretaria Municipal de Saúde do Município de Duque de Caxias (Rio de Janeiro). Patients were selected from among those who had been followed as outpatients for the prior three years, after serological diagnosis by two ELISA tests and one immunofluorescence examination done at the Laboratório Central Noel Nutels. Patients were asymptomatic in terms of the cardiovascular system. Patients with a past history of heart disease, hypertension $(\mathrm{H})$, acute myocardial infarction (AMI), valvar diseases, chronic alcoholism, diabetes mellitus and renal failure were excluded. The stage of the infection was assessed by a differential count of lymphocytes, which was performed using flow cytometry at the Laboratório Central Noel Nutels. According to the immunological stage, patients were divided into two groups: Group A, consisting of patients with CD 4 cell count $>500 / \mathrm{mm}^{3}$ and Group B, with a more advanced form of infection and presenting with systemic symptoms or associated infections and a CD4 cell count $<500 / \mathrm{mm}^{3}$. The results and variables of these patients were compared with a control group (Group C), consisting of healthy individuals with no antibodies present in the serum.

All patients underwent DE with ESAOTE SIM 7000 equipment, with pulsed and continuous Doppler and color flow mapping capability, in order to analyze systolic function by the fractional shortening of the LV, as well as global and segmental contractility of this chamber. Diastolic function was analyzed by the following parameters of the mitral valve flow: 1) E wave velocity, measured in $\mathrm{cm} / \mathrm{s} ; 2$ ) A wave velocity, also measured in $\mathrm{cm} / \mathrm{s} ; 3$ ) E/A ratio; 4) Deceleration Time of the E wave (DT); 5) Isovolumic Relaxation Time(IVRT).

M Mode measurements were taken according to the standards of the American Society of Echocardiography (ASE) ${ }^{43,44}$ and obtained by two-dimensional images and simultaneous electrocardiogram (ECG). LV diameters were obtained in the parasternal long axis view, with the M mode cursor positioned between the mitral valve and the papillary muscles. Thickness of the ventricular septum and the posterior wall of the LV and the left ventricular diastolic diameter were measured at the end of diastole (R wave in the ECG). The ventricular septal thickness was measured within the septum, and the diastolic diameter from the leading edge of the ventricular septum (endocardium included) to the leading edge of the posterior wall (endocardium excluded). Systolic diameter was measured from the maximal inferior displacement of the ventricular septum.

Measurements of the mitral valve inflow were performed in the four-chamber view, at the tips of the mitral leaflets, with the sample volume positioned inside the LV cavity, oriented by color Doppler ${ }^{44,45}$. The E wave was measured at the beginning of diastole (end of the T wave of the ECG). DT was measured from the peak of the E wave to its total deceleration. A wave was measured at the beginning of the QRS of the ECG. IVRT was obtained in the apical five-chamber view, with the sample volume positioned between the mitral inflow and the left ventricular outflow tract, oriented by color Doppler and measuring the time from the end of the aortic flow until the opening of the mitral valve (beginning of the $\mathrm{E}$ wave) ${ }^{45}$. 
Ejection fraction was automatically calculated by the existing software in the equipment, using the Teichholz formula.

Statistical analysis was performed using mean values and standard deviations, median value, minimal and maximal values and, for discrete variables, frequency distribution. To compare the results obtained and verify if there was statistical difference among the mean values of variables in Groups A, B and C, variance analysis and the Tukey test were used to establish the minimally significant difference between groups. The Spearman test was used to establish if there was a correlation between the E/A ratio in Group B and CD4 cell count.

\section{Results}

Among 375 patients registered in the program DST/ AIDS, 84 were selected according to the established protocol. Patients with $\mathrm{H}$ (89), diabetes mellitus (25), angina (16), chronic obstructive pulmonary disease (15), chronic renal failure (13), chronic alcoholism (12), valvar diseases (12) and arrhythmias (9) were excluded. In addition, 43 patients refused to participate in the study; 41 died before they completed the protocol; and in 11, the echocardiogram was technically inadequate due to the thorax of the patient or because of tachycardia secondary to infection at the time of the exam.

Age ranged from 18 to 59 (mean $34 \pm 9$ ) and patients were divided into two groups, according to their immunological compromise: Group A comprising 59 patients with CD4 cell count $>500 / \mathrm{mm}^{3}$ and Group B, 25 patients, with more advanced infection and CD 4 cell count $<500 / \mathrm{mm}^{3}$. There was no statistical difference in the age or the heart rate among the three groups (table I). All patients in Group B were on antiretroviral drugs. Results were compared with those obtained in 47 patients from the control group (group C).

Group B had a $31.5 \%$ incidence of LV systolic dysfunction, $8 \%$ of pericardial effusion and $12 \%$ of moderate mitral regurgitation. There was a significantly lower fractional shortening and higher LV systolic diameter in these patients $(\mathrm{P}<0.05$, table II $)$

The A wave velocity from the mitral flow was statistically different among groups, with a lower E/A ratio in

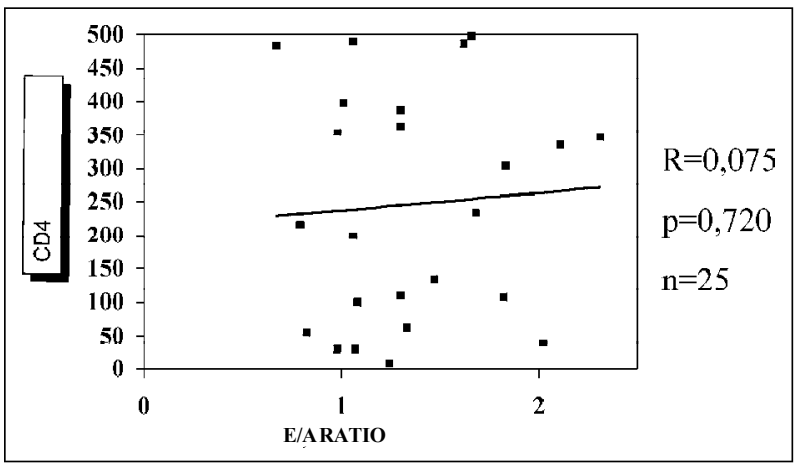

Fig. 1 - Correlation between CD4 cells count and the E/A ratio in HIV positive patients.

\begin{tabular}{|c|c|c|c|}
\hline & Group A $(n=59)$ & Group B $(n=25)$ & $\begin{array}{c}\text { Group C } \\
(\mathrm{n}=47)\end{array}$ \\
\hline Age (years)* & $34 \pm 9$ & $32 \pm 7$ & $34 \pm 11$ \\
\hline Male Sex \% & 57 & 60 & 30 \\
\hline White $\% *$ & 62 & 53 & 76 \\
\hline HR (bpm)* & $74 \pm 5$ & $82 \pm 6$ & $81 \pm 5$ \\
\hline
\end{tabular}

more advanced cases (Group B). But there was no statistical difference in the IVRT, and the DT was paradoxically decreased in Group B (table III).

\section{Discussion}

Several studies have shown the relationship between AIDS and the heart at some stage of the disease. Pericardial effusion and pericarditis are the most frequently recognized heart diseases in AIDS ${ }^{26-33}$. Pericarditis due to specific agents has been described, and Mycobacterium tuberculosis ${ }^{16,46}$ is the most frequently found agent. In a study of patients with clinical symptoms of heart disease, $22 \%$ had evidence of cardiac tamponade, and $33 \%$ had an important pericardial effusion ${ }^{16}$. In a series of 88 in-patients with AIDS at the San Francisco General Hospital, pericardial effusion was the most common abnormality, occurring in $30 \%$ of the patients ${ }^{47}$. In a prospective study by DE of patients with AIDS, pericardial effusion was found in 5\%, and this increased to $11 \%$ per year in the follow-up. These patients had a worse prognosis ${ }^{41}$ when compared with those who did not develop pericardial effusion during their follow-up (36\% versus $93 \%$ in six months), and this worse prognosis was independent of the CD4 cell count ${ }^{48}$. Recently, other authors have also described a worse prognosis in AIDS patients who develop pericardial effusion ${ }^{49}$. The etiology of pericardial effusion can vary and can be related to the infection by the HIV virus itself or to another opportunistic agent, such as Coxsackievirus or cytomegalovirus, or even cardiac involvement by a malign process associated with AIDS, such as Kaposi sarcoma. Cardiac tamponade may or may not occur $27,30,31,33$.

Cardiac involvement is one of the most controversial

\begin{tabular}{|lccc|}
\hline \multicolumn{4}{|c|}{ Table II - Morpho-functional data and systolic function } \\
\hline & Group A (n=59) & Group B (n=25) & Group C (n=47) \\
\hline LA (mc) & $2.9 \pm 0.3$ & $3.4 \pm 0.6$ & $3.1 \pm 0.6$ \\
LVd (cm) & $4.1 \pm 0.5$ & $4.4 \pm 0.8$ & $4.2 \pm 0.8$ \\
LVs (cm) & $2.7 \pm 0.3$ & $3.5 \pm 0.7 *$ & $2.5 \pm 0.7$ \\
$\Delta \mathrm{D} \%$ & $35.0 \pm 3.0$ & $28.0 \pm 2.0 *$ & $39.0 \pm 3.5$ \\
PE\% & - & 8.0 & - \\
Mild MR \%** & - & 12.0 & - \\
\hline LA-left atrium; LVd- left ventricular diastolic diameter ; LVs- left \\
ventricular systolic diameter; MR- mitral regurgitation; DD\%: fractional \\
shortening; PE- pericardial effusion; *p<0.05. \\
\hline
\end{tabular}




\begin{tabular}{|c|c|c|c|}
\hline \multicolumn{4}{|c|}{ Table IIII - Daistolic parameters in the studied groups } \\
\hline & Group A $(\mathrm{n}=59)$ & Group B $(n=25)$ & Group $(n=47)$ \\
\hline E wave $(\mathrm{cm} / \mathrm{s})$ & $76.07 \pm 20.62$ & $74.36 \pm 17.63$ & $75,55 \pm 15,39$ \\
\hline A wave* $(\mathrm{cm} / \mathrm{s})$ & $54.71 \pm 11.71$ & $57.16 \pm 11.53$ & $49,47 \pm 11,88$ \\
\hline E/A ratio $* *$ & $1.43 \pm 0.42$ & $1.35 \pm 0.43$ & $1,58 \pm 0,40$ \\
\hline IVRT(ms)*** & $78.03 \pm 16.92$ & $82.16 \pm 16.65$ & $83,32 \pm 14,50$ \\
\hline $\mathrm{DT}(\mathrm{ms})^{*}$ & $151.03 \pm 40.69$ & $142.44 \pm 35.98$ & $162,62 \pm 29,46$ \\
\hline
\end{tabular}

topics in AIDS. Cohen et al ${ }^{12}$ reported three cases of patients with AIDS who had clinical, structural and echocardiographic abnormalities suggestive of dilated cardiomyopathy (DCM). Microscopy showed inflammatory cells, myofibrillar atrophy and myocardial necrosis. Reilly et al ${ }^{15}$ described the autopsy of 58 patients with AIDS; $12 \%$ had cardiovascular abnormalities, including heart failure and arrhythmias. All had focal myocarditis at autopsy, which was believed to be of viral origin. Left ventricular dilation, heart failure and segmental or diffuse hypokinesis have been described ${ }^{28,37}$. De Castro et al ${ }^{50}$ in a prospective study of $137 \mathrm{HIV}$ - infected patients and 40 healthy controls noted that $7.3 \%$ of the patients developed cardiac symptoms characterized by heart failure; $5.1 \%$ had a DCM; $6.5 \%$ had global hypokenesis of the LV with or without dilation and $12.4 \%$ had segmental abnormalities of the left ventricular walls. These patients did not have risk factors or atherosclerotic coronary artery disease.

The physiopathology of the ventricular dysfunction in AIDS remains undetermined. The fact that the myocardial cell does not have a CD4 receptor contradicts the theory that HIV has a direct action on myocardial cells. Opportunistic infections, such as toxoplasmosis, cytomegalovirus and Epstein-Barr virus, can cause myocardial damage. ${ }^{32}$ Souto et al ${ }^{51}$ described a case of a man with AIDS who had a focal neurological problem and developed clinical signs of myocardial failure. His echocardiogram showed LV dysfunction, and he ultimately died. An anatomo-pathological examination of the heart showed degenerative abnormalities of the muscle fibers, lymphocytic focal infiltrates and the presence of Toxoplasma gondii. A Brazilian study of the clinical-pathological correlation, which aimed at analyzing myocardial abnormalities in patients with AIDS, retrospectively examined 50 patients, ages ranging from 3 months to 40 years, and reported myocarditis in 33 cases $^{52}$. Degenerative histological lesions were present in 17 patients. The etiological agents were as follows: toxoplasma in 11 cases, Cryptococcus in 7 and cytomegalovirus in 3 . In 12 cases, an etiological agent was not found, and 15 others had evidence of other lesions: endocarditis, pericarditis and Kaposi sarcoma.

Okoshi and Montenegro ${ }^{53}$ studied the incidence and etiology of the cardiac lesions in patients with AIDS in a retrospective study of 72 necropsies. In none of the necropsies was death considered secondary to the heart lesion, but macro- and microscopic abnormalities were found in $90 \%$ of the cases. Cardiac fiber atrophy, associated or not with interstitial edema and diffuse lipomatosis, was observed in $51 \%$ of the cases. In 13 cases, a probable etiological agent was demonstrated: Cryptococcus neoformans in three and Mycobacterium tuberculosis, atypical microbacteria, Toxoplasma gondii, Trypanosoma cruzi and cytomegalovirus in two each.

Recently, a prospective study where $952 \mathrm{HIV}$-infected patients were followed by DE to determine the incidence of DCM was published ${ }^{54}$. All patients with the diagnosis of DCM by DE underwent endomyocardial biopsy for histopathological, virological and immuno-histological study. Eight per cent of these patients developed DCM, and this incidence was higher in patients with a CD4 cell count $<400$ / $\mathrm{mm}^{3}$ and in those receiving zidovudine. A histopathological diagnosis of myocarditis was established in $83 \%$ of the patients with DCM. Hybridization in situ detected the HIV nucleic acid sequence in the myocytes of 58 patients, and 36 of these had active myocarditis. The authors concluded that DCM can be caused by the direct action of HIV on the myocardium or by an autoimmune process, possibly associated with other cardiotropic viruses. The examination of the heart in all these studies showed a high incidence of pathological abnormalities that can be found in AIDS. In addition to the direct action of HIV, of other opportunistic agents and of associated malign processes, other hypotheses have been offered. Myocardial damage can result from cytokinins released by HIV infected lymphocytes or monocytes, nutritional deficiency, autoimmune dysfunction, and the action of antiviral agents, such as AZT ${ }^{35,55-57}$.

In our study, the incidence of pericardial effusion in HIV- infected patients with a more advanced disease (CD4 cell count $<500 / \mathrm{mm}^{3}$ ) was $8 \%$, which was a lower percentage than previously reported in the literature, where pericardial effusion has been described as the most frequent finding. Our patients had a $31.5 \%$ prevalence of diffuse hypokinesis of the LV, with a significant increase in the systolic diameter of the LV, when compared with Group A patients (table II). HIV- infected patients with a CD 4 cell count $>500 / \mathrm{mm}^{3}$ had no structural abnormalities revealed by $\mathrm{DE}$.

Heart failure due to DCM was described in three patients with AIDS in $1986^{12}$. In the last few years, DE and autopsy studies have shown that systolic dysfunction is an 
important cause of morbidity and mortality in AIDS patients. Although the prevalence of systolic dysfunction in these patients seems to vary from 2 to $40 \%$, it is usually accepted that symptomatic heart failure will occur in approximately $5 \%$ of infected patients, especially in those in the end stage of the disease ${ }^{28,35}$.

In our study, we found a prevalence of LV systolic dysfunction of $31.5 \%$ in Group B patients. The fractional shortening of the LV was significantly lower in these patients, indicating a decrease in LV global systolic function (table II).

$\mathrm{LV}$ diastolic dysfunction has been described as the first abnormality of several cardiovascular diseases. In a research conducted by Coudray et al ${ }^{57}$, LV diastolic function estimated by DE in HIV patients showed an increase in the IVRT and a decrease in the $E$ wave velocity when compared with control patients. These data suggest an early myocardial involvement during HIV infection, without significant clinical impact. On the other hand, in a study involving 60 patients with AIDS, E/A ratio was mildly but significantly reduced in patients with advanced infection, while it was normal in control patients ${ }^{36}$.

In the present study we tried to correlate abnormalities of the mitral flow in HIV positive patients in two different stages of the disease. There was statistically a significant difference in the mean value of the A wave among the three groups, being higher in Group B patients, who also had a lower CD4 count. E wave velocity was not different among the three groups but the E/A ratio was significantly lower in Group B and C (table II). However, although the E/A ratio was statistically different, it remained in the normal range in Group B $(>1)$. DT was also found to be shorter in Group B, which is the opposite of what would be expected in the abnormal relaxation pattern of the LV. These discrepancies are probably related to the small number of patients, since the observed differences, although statistically significant, were very small. When we tried to correlate the $\mathrm{E} / \mathrm{A}$ ratio with the $\mathrm{CD} 4$ cell count using the Spearman test, we could not find a direct linear relationship between a probable ventricular relaxation abnormality and the stage of the disease. Patients with a very low CD4 cell count $\left(8 / \mathrm{mm}^{3}\right.$, for instance) had an E/A ratio in the range of 2 , while patients with a $\mathrm{CD} 4$ cell count close to normal had an $\mathrm{E} / \mathrm{A}$ ratio $<1 ; \mathrm{r}=0.075$, which corresponds to a $\mathrm{p}$ value of 0.720 (fig. 1 ).

Also, the IVRT, which is considered a much more reliable index of LV diastolic function, was not statistically different among the study groups (table II). Therefore, although a statistically lower E/A ratio was found, diastolic dysfunction in these patients could not be established. Not only the E/A ratio failed to correlate with the stage of the disease, but the observed changes were too small. In addition, other factors, such as dehydration, electrolyte abnormalities and even the use of some antiretroviral drugs, such as AZT, that can influence diastolic function, may have been present and influenced the mitral flow ${ }^{54,55}$.

In conclusion, in our study, where asymptomatic patients with HIV infection did not show significant Doppler echocardiographic abnormalities, HIV patients with a CD4 cell count $<500 / \mathrm{mm}^{3}$ had a higher incidence of pericardial effusion and of LV diffuse hypokinesis, suggesting a diffuse myocardial damage. This damage may be associated with an infectious agent (the virus itself or an opportunistic agent) or with the use of antiretroviral drugs in these patients. Other etiologies can not be disregarded, however, because other diseases were not ruled out in these patients. Up to the end of the study, patients remained asymptomatic, but a longer period of follow-up would have been necessary to detect symptomatic heart failure. The incidence of pericardial effusion was significant, but it was lower than previously reported in the literature. The abnormalities of the E/A ratio did not correlate with the immunosuppression stage of the disease, and we can not even state that abnormal diastolic relaxation was present in these patients.

\section{References}

1. Masur H, Michelis MA, Greene JB, et al. An outbreak of community-acquired Pneumocystis carinii pneumonia: manifestations of cellular immune dysfunction. N Engl J Med 1981; 305: 1431-8.

2. Gottlieb MS, Schroff R, Schanker HM, et al. Pneumocystis carinii pneu-monia and mucosal candidiasis in previously healthy homosexual men: evidence of a new acquired cellular immunodeficiency. N Engl J Med 1981; 305: 1425-31.

3. Popovic M, Sarnagadham MG, Read E, et al. Detection, isolation, and continuous production of cytopathic retroviruses (HTLV-III) from patients with AIDS and pre-AIDS. Science 1984; 224: 487-500.

4. WHO - The current global situation of the HIV/AIDS pandemic. Geneva: World ealth Organization, 1995.

5. Greene W. The molecular biology of human imunodeficiency virus type 1 infection. N Engl J Med 1991; 324: 308-15.

6. Mosman TR, Cherwinski H, Bond MW, et al. Two types of murine helper T cell clones: definition according to profiles of lymphokine activities and secreted proteins. J Immunol 1986; 136: 2348-57.

7. Lucey DR, Clereci M, Shearer GM. Type 1/type 2 cytokine dysregulation in human infectious, neoplastic, and inflammatory diseases. Clin Microbiol Ver 1996; 9: 532-62.

8. Embretson J, Zupancic M, Ribas JL, et al. CD4+ monocytes in HIV infection: a n early increase is followed by a progressive decline. J AIDS 1991; 4: 24-30.

9. Pantaleo G, Graziosi C, Demarest JF, et al. HIV infection is active and progressive in lymphoid tissue during the clinically latent stage of disease. Nature 1993; 362: 355-8.

10. Heath SL, Tew JG, Szakal AK, et al. Follicular dendritic cells and human immunodeficiency virus infectivity. Nature 1995; 377: 740-4.

11. Reichert CM, OíLeary TJ, Levens DL, et al. Autopsy pathology in acquired immune deficiency syndrome. Am J Pathol 1983; 112: 357-82.

12. Cohen I, Anderson D, Virmani R, et al. Congestive cardiomyopathy in association with the acquired immunodeficiency syndrome. N Engl J Med 1986; 315: 628-30.

13. Raffanti SP, Chiaramida Aj, Sem P, et al. Assessment of cardiac function in patients with the acquired immunodeficiency syndrome. Chest 1988; 93:592-594 
14. Fink L, Reichek N, St John Sutton MG. Cardiac abnormalities in acquired immunodeficiency syndrome. Am J Cardiol 1984; 54: 1161-3.

15. Reilly JM, Cunnion RE, Anderson DW, O'Leary TJ, Simmons JT, Lane HC. Frequency of myocarditis, left ventricular dysfunction and vetricular tachycardia in acquired immunodeficiency syndrome. Am J Cardiol 1988; 62: 789-93.

16. Monsuez JJ, Kinney EL, Vittecoq D, Kitzis M, Rozenbaum M, D'agay MF Comparison among acquired immune deficiency syndrome patients with and without clinical evidency of cardiac disease. Am J Cardiol 1988; 62: 1311-3.

17. Corboy JR, Fink L, Miller WT. Congestive cardiomyopathy in association wiyh AIDS. Radiology 1987; 165: 139-41.

18. Contans J, Marchand JM, Conri C, Peuchant E, Seigneur M, Rispal P. Asymptomatic atherosclerosis in HIV-positive patients: a case-control ultrasound study. Ann Med 1995; 27; 683-5.

19. Raaf HN, Raaf JH. Sarcomas related to the heart and vasculature. Semin Surg Oncoln 1994; 10: 374-82

20. Hecht SR, Berger M Tosh AV, Croxson S. Unsuspected cardiac abnormalities in the acquired immune deficiency syndrome, a n echocardiographic study. Chest 1989; 96: $805-8$.

21. Cammarosano C, Lewis W. Posmortem studies cardiac lesions in acquired immunedeficiency syndrome (AIDS). J Am Coll Cardiol 1985; 5: 703-6.

22. Anderson DW, Virmane R, Reilly, O'leary T, et al. Prevalence myocarditis at necropsy in acquired immunodeficiency syndrome. J Am Coll Cardiol 1988; 11: 729-9.

23. Baroldi G, Corallo S, Morani M, et al. Focal lymphocytic myocarditis in acquired immunodeficiency syndrome (AIDS): A correlative morphologic and clinic study in 26 consecutive fatal cases. J Am Coll Cardiol 1988; 12: 463-9.

24. Silver MA, Macher AM, Reichert CM, Levens DL, Parilo JE, Longo DL. Cardiac involvement by Kaposi's sarcoma in acquired immune deficiency syndrome (AIDS). Am J Cardiol 1984; 53: 983-5.

25. Hansen BF. Pathology of the heart in AIDS. A study of 60 consecutive autopsies. APMIS 1992; 100: 273-9.

26. Francis CK. Cardiac involvement in AIDS. Curr Probl Cardiol 1990; 15: 575-639.

27. Reynolds MM, Hecht SR, Berger M, Kolokathis A, Horowitz SF. Large pericardial effusions in the acquired immunodeficiency Syndrome. Chest 1992; 102: 746-7.

28. Himelman RB, Chung WS, Chernoff DN, Schiller NB, Hollander H. Cardiac manifestations of human immunodeficiency virus infection: A two-dimensional echocardiographic study. J Am Coll Cardiol 1989: 13: 1030-6.

29. Woods GL, Goldsmith JC. Fatal pericarditis due to mycobacterium aviumintracellulare in acquired immunodeficiency syndrome. Chest 1989; 95: 1355-7.

30. Eisenberg M, Gordon AS, Schiller NB. HIV associated pericardial effusions. Chest 1992; 102: 956-8.

31. Stotka JL, Good CB, Downer WR, Kapoor WN. Pericardial effusion and tamponade due to Kaposi's sarcoma in acquired immunodeficiency syndrome. Chest 1989; 96: 1351-69.

32. Wu TC, Pizzorno MC, Haywards GS, et al. In situ detection of human cytomegalovirus immediate early gene transcripts within cardiac myocytes of patients with HIV-associated cardiomyopathy. AIDS 1992; 8: 777-85.

33. Mast HL, Haller JO, Schiller MS, Anderson VM. Pericardial effusion and its relationship to cardiac disease in children with acquired immunodeficiency syndrome. Pediatr Radiol 1992; 22; 548-51.

34. Martos A, Carratala J Cabellos C, Rodriguez P. AIDS and primary hypertension. Am Heart J 1993; 125: 1819

35. Herskowitz A, Vlahovr D, Willughby S, et al. Prevalence and incidence of left ventricular dysfunction in patients with human immunodeficiency virus infection. Am J Cardiol 1993; 17: 955-8.

36. Thuesen L, Moller A, Kristensen BO, Black F. Cardiac function in patients with human immunodeficiency virus infection and with no other active infections. Dan Med Bull 1994; 41: 107-9.

37. Fong IW, Howard R, Elzawi A, Simbul M, Chiassond D. Cardiac involvement in human immunodeficiency virus-infected patients. J Acquir Immune Defic Syndr 1993; 6: 380-5.

38. Willoughby SB, Vlahov D, Herskowitz A. Frequency of left ventricular dysfunction and other echocardiographic abnormalities in human immunodeficiency virus seronegative intravenous drug users. Am J Cardiol 1993; 71: 446-7.

39. Corallo S, Mutinellli MR, Moroni M, et al. Echocardiography detects myocardia damage in AIDS: Prospective study in 102 patients. Eu Heart J 1988; 9: 887-92.

40. Blanchard DG, Hagenhoff C, Chow LC, et al. Reversibility of cardiac abnormalities in human immunodeficiency virus (HIV) infected individuals: A serial echocardiographic study. J Am Coll Cardiol 1991; 17: 1270-6.

41. Abreu A, Serrano A, Nunes H, et al. Anechocardiographic comparison of left ventricular function in HIV-virus carrers and infecterd patients in different stages of immunosuppression. Rev Port Cardiol 1995; 14: 725-8.

42. Sahn DJ, De Maria A, Kisslo J, Weyman A. Recommendations regarding quantitation in M-mode echocardiography: Results of a survey of echocardiographic measurements. Circulation 1978; 58: 1972-83.

43. Schiller NB, Shah PM, Crawford M, et al. Recommendations for quantitation of the left ventricle by two-dimensional echocardiography. J Am Soc Echocardiogr 1989; 5: 362-75.

44. Harrison MR, Smith MD, Grayburn PA, et al. Normal blood flow patterns by color Doppler flow imaging. Echocardiography 1987; 4: 485- 92.

45. Sasson Z, Hatle L, Appleton CP, et al. Intraventricular flow during isovolumic relaxation: description and characterization by Doppler echocardiography. J Am Coll Cardiol 1987; 10:539-46.

46. D'Cruz IA, Sengupta EE, Abrahams C, Reddy HK, Turlapati RV. Cardiac involvement, including tuberculous pericardial effusion, complicating acquired immune deficiency syndrome. Am Heart J 1986; 112: 1100-2.

47. Cheitlin MD. AIDS and the cardiovascular system. In: Alexander RW, Schlant RC, Fuster V, eds - Hurst's the Heart, Arteries, and Veins. $9^{\text {th }}$ edition. New York: The McGraw-Hill Co., 1998: 2145.

48. Heidenreich PA, Eisenberg MJ, Kee LL, et al. Pericardial effusion in AIDS Incidence and survival. Circulation, 1995; 92: 3229-34.

49. Flum DR, McGinn JT Jr, Tyras DH. The role of the "pericardial window" in AIDS Chest, 1995; 107: 1522-5.

50. De Castro S, d'Amati G, Cartoni D, et al. Frequency of development of acute global left ventricular dysfunction in human immunodeficiency virus infection. J Am Coll Cardiol, 1994; 24: 1018-24.

51. Souto FJD, Salermo HD, Andrade JA, Melo LMC. Myocarditis due to toxoplasma gondii in a man with acquired immunodeficiency syndrome. Arq Bras Cardiol, 1991; 57: 399-402

52. Herdy GVH, Ramos R, Bazin AR, et al. Clinicopathologic correlation in 50 cases of aquired immunodeficiency syndrome: retrospective study. Arq Bras Cardiol, 1994; 62: 95-8

53. Okoshi MP, Montenegro MR. Pathology of the heart in AIDS. Astudy of 73 consecutive necropsies. Arq Bras Cardiol 1996, 66: 129-33.

54. Giuseppe B, Gabriella DL, Benvenuto G, Giorgio B. Incidence of dilated cardiomyopathy and detection of HIV in myocardial cells of HIV-positive patients. N Engl J Med 1998; 339: 1093-9.

55. Acierno LJ. Cardiac complications in acquired immunodeficiency syndrome (AIDS): A review. J Am Coll Cardiol 1989; 13: 1144-54

56. Lipshultz SE, Orav EJ, Sanders SP, Hale AR, Mcintosh K, Colan SD. Cardiac struture and function in children with human immunodeficiency virus infection treated with Zidovudina. N Engl J Med 1992; 327: 1260-5.

57. Coudray N, de Zuttere D, Force G, et al. Left ventricular diastolic function in asymptomatic and symptomatic human immunodeficiency virus carries: An echocardiographic study. Eur Heart J 1995; 16: 61-7.

58. Herskowitz A, Willoughby SB, Baughman KL, et al. Cardiomyopathy associated with antiretroviarl therapy in patients with HIV infection: A report of six cases. Ann Intern Med 1992; 116: 311-3. 